\title{
Problem Gambling and Gambling Addiction are not the Same
}

\author{
Mark D. Griffiths* \\ International Gaming Research Unit, Psychology Division, Nottingham Trent University, United Kingdom
}

*Corresponding author: Griffiths, M.D. International Gaming Research Unit, Psychology Division, Nottingham Trent University, Burton Street, Nottingham, NG1 4BU, United Kingdom; E-mail: mark.griffiths@ntu.ac.uk

Received Date: November 30, 2015 Accepted Date: December 19, 2015 Published Date: December 23, 2015

Citation: Griffiths, M.D. Problem Gambling and Gambling Addiction are not the Same. (2016) J Addict Depend 1(2): $37-39$.

\section{Introduction}

In the latest (fifth) edition of the Diagnostic and Statistical Manual of Mental Disorders ${ }^{[1]}$, gambling disorder (formerly pathological gambling) was reclassified from a disorder of impulse control to a behavioral addiction. This is an important move as it now means that potentially addictive behaviors that do not involve the ingestion of a psychoactive substance could theoretically be included as a behavioral addiction in future editions of the DSM (e.g., video game addiction, exercise addiction, sex addiction, work addiction).

In the gambling studies field, addictive gambling has tended to be associated with activities that have high event frequencies where individuals that have the time and money can gamble continuously on their preferred games such as slot machines, roulette, and blackjack every few seconds or minute ${ }^{[2-5]}$. Discontinuous games with low event frequencies such as weekly lottery games and football pools are much less likely to be addictive as individuals playing such games only find out the result of the gamble once or twice a week ${ }^{[2-5]}$.

Throughout my career, I have always asserted that I met very few people that I would consider as genuinely addicted to playing weekly or bi-weekly Lotto game ${ }^{[6]}$. When stating this, some people counter my assertion by saying that they know individuals who spend far too much money on buying Lotto tickets and that it is a real problem in their life. However, this is a classic instance of confusing 'problem gambling' with 'gambling addiction'. These two terms are not inter-changeable. When I give lectures on gambling addiction I always point out that "all gambling addicts are problem gamblers but not all problem gamblers are gambling addicts".

Nowhere is this more relevant than when disseminating the results of empirical research in the print and broadcast media. For instance, I have been one of the co-authors on the last two British Gambling Prevalence Surveys ${ }^{[7,8]}$ that have examined gambling behavior in-depth using a nationally representative sample of participants. In the most recent survey ${ }^{[8]}$, the prevalence rate of problem gambling was assessed using two different problem gambling screens - the DSM-IV criteria for problem gambling ${ }^{[9]}$ and the Problem Gambling Severity Index ${ }^{[10]}$. Neither of these screens assesses 'gambling addiction' and problem gambling is operationally defined according to the number of criteria endorsed on each screen. For instance, any individual that endorsed three or more items (out of ten) on the DSM-IV criteria was classed as a problem gambler. Any individual that endorsed five or more items was classed as a pathological gambler. Pathological gambling is more akin to gambling addiction but only a tiny percentage of such individuals were classed as such. We reported that $0.9 \%$ of individuals in the sample were problem gamblers (i.e., they scored three or more on the DSM-IV criteria).

What we did not say (and never have said) was that $0.9 \%$ of British adults (approximately 500,000 people) are "addicted" to gambling. However, many stories in the British media when they talk about problem gambling will claim 'half a million adults in Great Britain are gambling addicts' (or words to that effect). I am not trying to downplay the issue of gambling addiction. I know only too well the pain and suffering it can bring to individuals and their families. Also, just because I may not define a problem gambler as being genuinely addicted that does not mean that their problem gambling might not be impacting in major negatively detrimental ways on their life (e.g., relationship problems, financial problems, work problems, etc.). 
However, returning to the issue of being "addicted" to weekly or bi-weekly Lotto games, I have always stated in papers on both addiction ${ }^{[11]}$ and (more specifically) gambling addiction ${ }^{[3,4,12]}$, that addictions rely on constant rewards. A person cannot be genuinely addicted unless they are receiving constant rewards (i.e., their behavior being reinforced). Playing a Lotto game in which the result of the gamble is only given once or twice a week is not something that can provide constant rewards. A person can only be rewarded (i.e., reinforced) once or twice a week. As noted above, Lotto games are discontinuous and have a very low event frequency. Continuous gambling activities (like the playing of a slot machine) have very high event frequencies (e.g., a typical slot machine in the UK has an event frequency of 10-12 times a minute).

That does not mean individuals cannot spend too much money buying lottery tickets. Buying ticket after ticket can indeed lead people to have a gambling problem with Lotto. However, I know of no addiction criterion that relates to the amount of money spent engaging in an activity. Obviously the lack of money can lead to some signs of problematic and/or addictive behavior (such as committing criminal activity in order to get money to gamble if the individual does not have enough disposable income), but this is a consequence of the behavior not a criterion in itself. In most of the behavioral addictions that I carry out research into (e.g., exercise addiction, sex addiction, video game addiction, etc ${ }^{[11]}$, there is little money spent but some of these behaviors for a small minority of people appear to be genuine addictions.

One of the reasons I felt the need to write this editorial was a press release from the Salvation Army in New Zealand ${ }^{[13]}$. The story said that for some people, playing Lotto was an addictive activity:

"The Salvation Army Problem Gambling service is seeing an increase in the number of clients for whom Lotto products has become a problem for them and their families. 'When it becomes an addiction, gambling creates havoc in people's lives', says Commissioner Alistair Herring, National Director of Addiction Services. 'The gambling of some of our clients has led to criminal offending, domestic violence, loss of the family home, and most commonly children going without food and other basic needs. Regrettably, some people are unable to buy a simple product like a Lotto ticket without it leading to harm for themselves and others. A Lotto ticket can seem harmless but once their purchase becomes an addiction the results can be devastating '...In the past year, The Salvation Army problem gambling programme assisted over 1400 clients most of whom used Lotto. Fifty-seven clients said Lotto was the most significant aspect of their gambling problem. 'This sort of sales promotion without fully understanding the damage the product can have on an individual and their family is irresponsible. New Zealand is moving toward food labelling that identifies additives dangerous to health. Yet Lotto tickets are sold without any warning that they can lead to health dangers through addiction'. One of the results of Lotteries Commission activity is that Countdown supermarkets recently started selling Lotto tickets at the checkout".

Many reading this editorial may think I am being pedantic but while I do not doubt that buying too many Lotto tickets can be problematic if the person buying them simply cannot afford it, the resulting behavior is 'problem gambling' not 'gambling addiction'. In relation to my own criteria for addiction that include salience, mood modification, tolerance, withdrawal, conflict and relapse ${ }^{[11]}$, the only way someone could be addicted to Lotto was if they were actually addicted to the buying of the tickets rather than the outcome of the gamble itself. This is not as unlikely as it sounds because some of our research studies have shown that a small proportion of adolescents (aged 11 to 15 years) may be addicted to both playing Lotto games and scratchcardgames $^{[14,15]}$.

While it is theoretically possible for adolescents to be addicted to lottery scratchcards (as they can play continuously if they have the time, money, and opportunity), we found it strange that adolescents should have 'addiction' problems with Lotto. However, in a follow-up study utilizing qualitative focus groups ${ }^{[16]}$, some adolescents reported that they actually got a 'buzz' from the buying of Lotto tickets and scratch cards because it was an illegal activity for them (i.e., only those aged 16 years or older can play lottery games in the UK so the buying of tickets below this age is a criminal offence). Basically, there was a very small minority of kids that were hooked on the illegality of buying lottery tickets rather than the gambling itself.

More recently, I argued that game type is actually irrelevant in the development of gambling problems and gambling addiction and that it is the game's structural characteristics (rather than the game itself) that are most relevant. To demonstrate this, the following two examples demonstrate that structural characteristics (rather than the game type itself) are critical in the acquisition, development and maintenance of problem and pathological gambling for those who are vulnerable and/or susceptible ${ }^{[2]}$. For instance, a 'safe' slot machine could be designed in which it would be highly unlikely that an individual would ever develop a gambling problem. The simplest way to do this would be to ensure that whoever was playing the slot machine could not press the 'play button' or pull the lever more than once a week. An enforced structural characteristic of an event frequency of once a week would almost guarantee that players could not develop a gambling problem or gambling addiction. Alternatively, a problematic form of lottery game could be designed where instead of the draw taking place weekly or bi-weekly, it would be designed to take place once every few minutes. Such an example is not hypothetical and resembles lottery games that already exist in a number of jurisdictions in the form of rapid-draw lottery games like keno ${ }^{[2]}$.

Although many people (including those that work in both academia and the media) may still use the terms 'problem gambling' and 'gambling addiction' interchangeably, hopefully I have demonstrated here that there is a need to think of these terms as lying along a continuum in which 'gambling addiction' is at the extreme end of the scale and that 'problem gambling' (while still of major concern) does not necessarily lead to problems in every area of an individual's life.

\section{References}

1. American Psychiat Associat Diagnostic and Statistical Manual of Mental Disorders ( $5^{\text {th }}$ edition) (DSM-5). (2013) .

2. Griffiths, M.D., Auer, M. The irrelevancy of game-type in the acquisition, development and maintenance of problem gambling. (2012) Front Psychol 3: 621.

3. Parke, J., Griffiths, M.D. The psychology of the fruit machine: The role of structural characteristics (revisited). (2006) Int J Ment Health Addict 4: 151-179. 
4. Parke, J., Griffiths, M.D. The role of structural characteristics in gambling. In G. Smith, D. Hodgins \& R. Williams (Eds.), Research and Measurement Issues in Gambling Studies. (2007) New York: Elsevier pp: 211-243.

5. McCormack, A., Griffiths, M.D. A scoping study of the structural and situational characteristics of internet gambling. (2013) Int J Cyber Behav Psychol Learning 3(1): 21.

6. Griffiths, M.D., Wood, R. The psychology of lottery gambling. (2001) Int Gambl Studies 1(1): 27-45.

7. Wardle, H., Sproston, K., Orford, J., et al. The British Gambling Prevalence Survey 2007. (2007) london: The Stationery Office.

8. Wardle, H., Moody, A., Spence, S., et al. British Gambling Prevalence Survey 2010. London (2011) The Stationery Office.

9. American Psychiat Asso Diagnostic and Statistical Manual for Mental Disorders ( $4^{\text {th }}$ Edition) (1994).

10. Ferris, J., Wynne, H. The Canadian Problem Gambling Index User Manual. Report to the Canadian Inter-Provincial Task Force on Problem Gambling, Ottawa, ON (2001) The Canadian Centre on Substance Abuse.
11. Griffiths, M.D. A 'components' model of addiction within a biopsychosocial framework. (2005) J Sub Use 10(4): 191-197.

12. Griffiths, M.D. Gambling addictions. In A. Browne-Miller (Ed.), The Praeger International Collection on Addictions (2009) Behavioral Addictions from Concept to Compulsion pp. 235-257.

13. Salvation Army. Buying Lotto...Winning a gambling addiction. (2014) Scoop.

14. Wood, R. T., Griffiths, M.D. The acquisition, development and maintenance of lottery and scratch card gambling in adolescence. (1998) J Adolesc 21(3): 265-273.

15. Wood, R. T., Griffiths, M.D. Adolescent lottery and scratchcard players: Do their attitudes influence their gambling behaviour? (2004) J Adolesc 27(4): 467-475.

16. Wood, R.T., Griffiths, M.D. Adolescent perceptions of the National Lottery and scratchcards: A qualitative study using group interviews. (2002) J Adolesc 25(6): 655-668. 